\title{
Harnessing the creative potential of consumers: money, participation, and creativity in idea crowdsourcing
}

\author{
Oguz Ali $\operatorname{Acar}^{1}$ (D) \\ Published online: 26 April 2018 \\ (C) The Author(s) 2018
}

\begin{abstract}
Given the growing importance of innovation and consumer engagement, many firms are strongly interested in finding ways to encourage their consumers to generate creative new product ideas for them in their crowdsourcing initiatives. To that end, managers often use monetary rewards - one of the most commonly used managerial tools to stimulate desired behaviors. A critical question in this respect is whether the use of monetary rewards is effective in stimulating creativity and, if so, how large those rewards should be. This study aims to answer these questions. The results of an experiment suggest that introducing monetary rewards does not contribute to the number of new product ideas generated by a single consumer or the novelty of his/ her ideas, and when the reward is relatively small, it can even be harmful. Monetary rewards, however, are effective in encouraging widespread participation in crowdsourcing initiatives and improving the appropriateness of the new product ideas. As a whole, these findings take us a step further toward better understanding the motivational mechanisms of consumer creativity in new product ideation.
\end{abstract}

Keywords Reward · Motivation · Ideation · Consumer creativity $\cdot$ Crowdsourcing $\cdot$ User innovation

\section{Introduction}

A growing number of firms are using crowdsourcing to involve consumers in their new product ideation efforts (Bayus 2013; Huang et al. 2014). Such practices not only hold great potential for tapping into consumer creativity but also help firms to build stronger

Oguz Ali Acar

oguz.acar@city.ac.uk

1 Cass Business School, City, University of London, 106 Bunhill Row, London EC1Y 8TZ, UK 
connections with their customers (Acar and Puntoni 2016; Bayus 2013; Fuchs et al. 2010; Poetz and Schreier 2012; Stephen et al. 2016). ${ }^{1}$ Leveraging these benefits of crowdsourcing depends of course on being able to motivate consumers to take part in crowdsourcing initiatives. To that end, some firms offer extremely generous rewards for creative ideas. For example, Frito-Lay organizes "Do Us A Flavor" ideation contests where $\$ 1$ million is offered for the best new flavor suggestion for potato chips. Other firms, however, offer only modest rewards for comparable tasks - e.g., on the eYeka crowdsourcing platform, Knorr offered 2500 Euros for a revolutionary idea for a hot savory snack. Other firms such as Starbucks and Dell provide no monetary rewards at all for creative ideas that are submitted to their online communities (i.e., MyStarbucks Idea and Dell IdeaStorm).

As the examples above clearly indicate, managerial practices in terms of rewarding consumer creativity in ideation activities are far from uniform. In addition, research on the relationship between rewards and creativity has not provided a clear answer regarding the effectiveness of providing monetary rewards for creative tasks. As such, it remains unclear whether firms should offer monetary rewards in their crowdsourcing initiatives and, if so, how sizable those rewards should be. Drawing on an experiment in which participants generated new product ideas in return for real prizes, this paper aims to answer these questions and explores whether money can buy participation and creativity in crowdsourcing platforms. The results suggest that monetary rewards (compared to no monetary rewards at all) can be effective in (1) stimulating greater participation in crowdsourcing initiatives and (2) motivating consumers to create more useful ideas, provided the rewards are large enough. In terms of stimulating novelty and motivating consumers to generate multiple ideas, however, even sizable rewards appeared to have no effect, and smaller rewards could even be detrimental.

\section{Related literature}

\subsection{Monetary rewards and creativity}

Psychology research on the relationship between rewards and creativity divides broadly into mainly into two opposing camps and provides conflicting recommendations (see Byron and Khazanchi 2012 for a meta-analysis). While some scholars, often drawing on self-determination theory, have postulated that rewards are detrimental to creativity (Amabile 1996; Hennessey and Amabile 2010), others have argued that rewards in fact enhance creativity (Eisenberger and Armeli 1997; Eisenberger and Aselage 2009). In one of the few studies focusing specifically on creativity in the new product ideation context, Burroughs et al. (2011) found that the positive effects of monetary rewards on creativity were dependent on creativity training being provided in conjunction with the reward. It is worth noting that earlier experimental studies on the link between rewards and creativity focused almost exclusively on comparing the effects of offering or not offering a reward (i.e., on the presence of a reward). Very few of the experiments which compared the effects of different sizes of reward (Eisenberger and Armeli 1997; Eisenberger and Selbst 1994) also involved creativity training before tasks were

\footnotetext{
${ }^{1}$ Crowdsourcing may also have other benefits such as helping firms gain publicity.
} 
undertaken. Given that creativity training has already been found to moderate the relationship between rewards and creativity (Burroughs et al. 2011), it was not possible in these studies to determine which of the effects may have been particular to reward size and how reward size may have influenced creativity when no training was provided.

\subsection{Monetary rewards in crowdsourcing}

This line of research has focused mainly on identifying the optimal prize structure for incentivizing contest participants to do their best in crowdsourcing contests. More specifically, scholars have examined whether a fixed sum should be provided to a single winner (a winner-takes-all award structure) or whether the prize money should be distributed among various participants (i.e., a multiple-prize award structure) (e.g., Ales et al. 2017; Terwiesch and $\mathrm{Xu}$ 2008). Terwiesch and $\mathrm{Xu}$ (2008) found, for example, that for ideation projects (the type which we focus on in this paper), a winner-takes-all structure is the best strategy. Ales et al. (2017), however, showed that multiple prizes may work better than winner-takes-all prizes in certain circumstancesas, for example, when the crowd perceives that popularity with consumers is important in assessing ideas (which is often the case, as most crowdsourcing initiatives allow and indeed encourage other consumers to vote on the ideas put forward-e.g., Lego Ideas, "Do Us A Flavor" contest). As a whole, although this research extended our understanding of how prize money should be distributed among winners in crowdsourcing contests, it did not answer the question as to what role the presence and size of monetary rewards play in driving the generation of creative ideas.

\subsection{Monetary rewards for noncreative tasks}

In the context of noncreative tasks, there is extensive evidence from the economics literature to suggest that the size of monetary reward enhances people's effort and performance in the activity for which the reward is being given (e.g., Lazear 2000; Prendergast 1999). However, this view has been challenged recently (Gneezy and Rustichini 2000; Heyman and Ariely 2004). In their seminal paper, Gneezy and Rustichini (2000) provide an account of how rewards can have different effects, depending on their size. That is, unless it is sufficiently generous, a monetary reward might lead to a poorer performance than no reward at all. It is, however, not clear whether this can be extrapolated directly to creative tasks. This is because motivating individuals to be creative may be different from motivating them for routine performance, due to the particular cognitive and behavioral processes that underlie creativity: creative tasks are more dependent on intrinsic motivation, more risky, and more cognitively demanding (Byron and Khazanchi 2012).

\section{New product ideation experiment}

I recruited 302 adults (142 female) from an online crowdsourcing platform for human intelligence tasks (HITs), Amazon Mechanical Turk, in exchange for a small payment. The recruitment was for an unrelated filler task-i.e., completing a survey about their 
thoughts and beliefs. Once the participants had answered the questions in the filler task, they received a note indicating clearly that the task was over and that they would receive their payment. At the end of the note, they were told that there was an idea generation contest (separate from the task they had just completed) and that, if they wanted to, they could also participate in that.

Participants saw an invitation to take part in an idea generation contest to come up with a new flavor idea for a potato chip. This choice was informed by actual contests such as "Do Us a Flavor" contest. Participants were randomly assigned to receive one of three versions of the invitation, designed to manipulate the rewards. All the information was identical, except that in the low and high reward conditions, participants were given additional information specifying the amount they could potentially win. No such information was provided to those in the no reward condition. The main part of the invitation read as follows:

Do you have a great flavor idea for potato chips? Share it to join us in our endeavor to create "the best" potato chips in the world. We expect to receive about 100 ideas and will ask a panel of consumers to select the top 3 most creative flavors. We will let you know if you are the creator of one of the "winners."

As noted, in the low and high reward conditions, participants also received details of the prizes (i.e., "Here are the prizes for winners..."). Specifically, those in the low reward category were informed that there was total prize money of $\$ 40$, and that they stood a chance of winning either $\$ 25$ (first prize), \$10 (second prize), or $\$ 5$ (third prize). Those in the high reward category were told that the total sum available was $\$ 400$, and that they might win either $\$ 250$ (first prize), $\$ 100$ (second prize), or $\$ 50$ (third prize). The decision to offer multiple rewards, rather than a single prize for the overall winner, was prompted by previous marketing research on the link between rewards and creativity in new product ideation (Burroughs et al. 2011) and by actual crowdsourcing practice (e.g., "Do Us A Flavor" contest and contests on the eYeka and Tongal platforms, among others). The amounts offered were determined based on a pretest with 42 participants ( 26 female) recruited from the same population as our study participants. In the pretest, participants were asked to rate different prizes (presented in a random order) on a seven-point scale ( $1=$ very low, 4 = about right, 7 = very high). The prize structure for the high reward was perceived to be about right $(M=4.07, \mathrm{SD}=1.80$; not significantly different from the mid-point, $p>.25$ ), and the structure for low reward condition was perceived to be low $(M=2.43, \mathrm{SD}=1.60$; significantly lower than the mid-point, $p<.001)$. Importantly, the invitation included information about the expected number of contestants (i.e., “... we expect to receive about 100 ideas”), because participants might expect more competition in the high reward condition and this might influence how they rated their chances of winning.

After they had been given this information, participants were asked whether they wanted to take part. A total of 145 participants (79 female) decided to take part, but only 141 of them (77 female) actually submitted at least one idea. Those who chose to participate were given more details about the idea generation task and the rules of the contest (i.e., the evaluation criteria and submission requirements) which were adapted 
from a real crowdsourcing contest (i.e., "Do Us A Flavor"). All the participants were given the following information:

Thank you for agreeing to share your creative idea(s) with us. Please share your new flavor idea for a potato chip below. Please make sure your idea consists of (1) flavor name, (2) ingredients and (3) a brief description (why you think this makes a great flavor). A panel of consumer judges will evaluate every new flavor idea based on:

- its potential for a delicious flavor for potato chips

- originality of the flavor compared to other flavors in the market.

The top three ideas that have the highest cumulative score in these two criteria will be selected as winners. Feel free to enter as many ideas as you wish.

\section{Results}

\subsection{Participation}

As described in the previous section, participants were first given information about the contest and then asked whether they would like to participate. The answer to this question was coded as 0 if a respondent chose not to participate and 1 if he or she chose to participate. I conducted a logistic regression analysis to assess the effect of different monetary reward conditions on participants' likelihood of taking part in the idea generation contest. I used the high reward condition as the baseline condition and used dummy variables to represent the low reward and no reward conditions. The high, low, and no reward conditions had 101, 101, and 100 participants respectively. A test of the full model against the intercept-only model was significant, suggesting that the reward conditions affected consumers' likelihood of participating $\left(\chi^{2}(2)=14.14 ; p=.001\right)$. As depicted also in Fig. 1, participants in the high reward condition were more likely to take part in the contest than those in the no reward (61 vs. $36 \% ; B=-1.04$; odds ratio $=.35 ; p<.001)$ and low reward condition $(61$ vs. $43 \% ; B=-.76$; odds ratio $=.46$; $p=.008)$. A separate logistic regression analysis, in which the no reward condition was used as the baseline, showed that the likelihood of participating in the contest was not significantly different in the low reward and no reward conditions $(B=.28$; odds ratio $=$ $1.32 ; p>.25)$. These results suggest that monetary rewards can be used to attract more people to participate in a crowdsourcing contest as long as the reward is sufficiently high.

\subsection{Number of ideas generated}

In the task, participants were free to generate as many ideas as they liked, and the number of unique ideas submitted by each participant was coded. The number of ideas (also sometimes referred to as fluency) is often considered to be indicative of creativity 


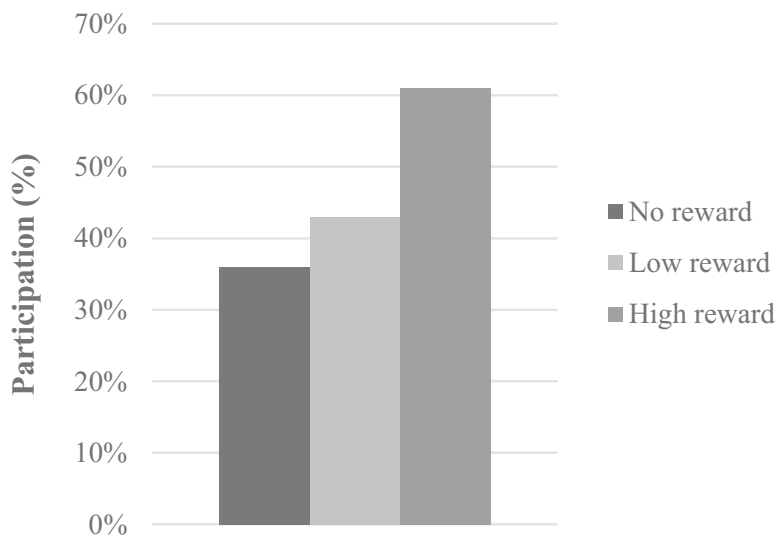

Fig. 1 Effect of monetary rewards on participation

(Guilford 1967) and has been used extensively in the prior literature (e.g., Mehta et al. 2012; Toubia 2006). The no reward, low reward, and high reward conditions had 36 , 43, and 62 participants respectively. To account for non-normality, I conducted a nonparametric Kruskal-Wallis test for three independent samples. The results showed a statistically significant difference in number of ideas generated across different reward conditions $\left(\chi^{2}(2)=7.29, p=.026\right)$. Participants in the low reward condition generated significantly fewer ideas per person $(M=1.02, \mathrm{SD}=.15)$ than those in either the no reward $\left(M=1.39, \mathrm{SD}=.90 ; \mathrm{Z}_{\text {Mann-Whitney }}=2.78, p=.005\right)$ or high reward $(M=1.32$, $\left.\mathrm{SD}=.83 ; \mathrm{Z}_{\text {Mann-Whitney }}=2.30, p=.021\right)$. No significant difference was observed between the no reward and high reward conditions ( $p>.25)$ (Fig. 2).

\subsection{Novelty and appropriateness of ideas}

Creative ideas are considered to have two main components - novelty (i.e., originality, uniqueness) and appropriateness (i.e., usefulness, effectiveness) (Hennessey and Amabile 2010). In line with recent marketing research (e.g., Mehta and Zhu 2016;

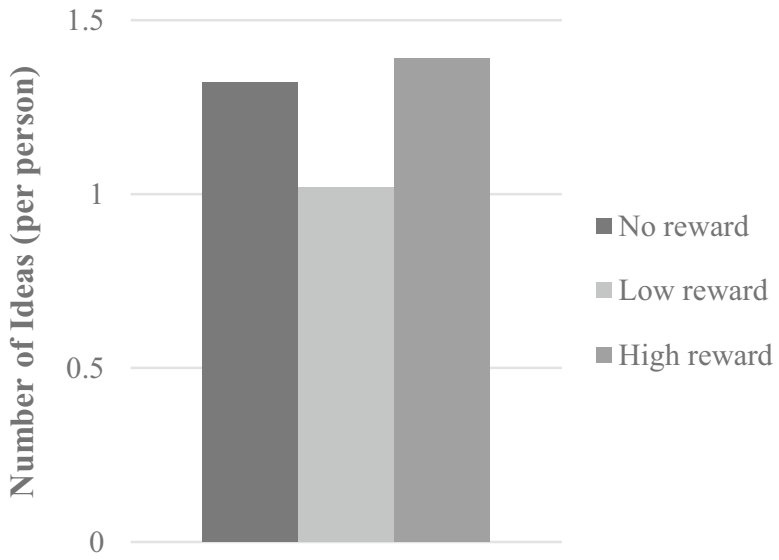

Fig. 2 Effect of monetary rewards on number of ideas 
Moreau and Dahl 2005), I used separate ratings by independent judges to measure these two dimensions (instead of having a single score for creativity). In particular, I recruited five judges from the same population as our study participants to assess the novelty and appropriateness of each idea. The judges were given no information about the identity of the participants or the other judges, nor were they told about the conditions of the experiment. The only information that I provided to the judges was a spreadsheet of the participants' ideas (in random order) and details of the experimental task and evaluation criteria. Judges were asked to rate each idea in terms of its novelty and its appropriateness, using a scale developed by Moreau and Dahl (2005). For novelty, the three items in the measure were originality, innovativeness, and creativity, and for appropriateness, the items were practicality, likely effectiveness, and usefulness; all items were scored using a seven-point scale ( $1=$ not at all, $7=$ very) (see Table 1 for a list of example ideas). To create a novelty and appropriateness index for each participant, I followed the procedures outlined by Mehta and Zhu (2016, 2009). I averaged each of the five judges' ratings on three items for novelty/appropriateness to obtain five novelty/appropriateness scores for each idea. These scores were then averaged to obtain an overall score for both novelty and appropriateness ( $\alpha=.79$ and $\alpha=.69$ respectively). When a participant submitted multiple ideas, an average score for novelty and appropriateness was calculated for that participant by summing up novelty/appropriateness score for each of the ideas and dividing it by the total number of ideas he or she had generated.

A Kruskal-Wallis test for three independent samples returned a significant main effect of monetary rewards on the novelty and appropriateness of the ideas generated $\left(\chi^{2}(2)=9.02, p=.011\right.$ and $\chi^{2}(2)=12.75, p=.002$ respectively). Compared to those generated in the low reward condition $(M=4.78, \mathrm{SD}=1.36)$, the ideas generated by the participants in the high reward condition $\left(M=5.35, \mathrm{SD}=1.07 ; \mathrm{Z}_{\text {Mann-Whitney }}=2.18\right.$, $p=.029)$ and no reward condition $\left(M=5.54, \mathrm{SD}=1.09 ; \mathrm{Z}_{\text {Mann-Whitney }}=2.75, p=.006\right)$ were judged to be significantly more novel. The differences in novelty judgments between the high reward and no reward conditions were not significant $(p>.25)$. The

Table 1 Selected ideas from the experiment

Some of the winning (i.e., most creative) ideas

Pad Thai: Ingredients would include flavors like tamarind, spring onion, a little brown sugar, garlic, fish sauce, and lime. I would love to try a chip like this. I imagine them having a little sweet background with some good umami flavors built in, with a finish of lime. I have seen quite a few different flavors of chips developed but none of them seem to get very creative with different ideas about cuisine.

Pesto and Ricotta Ravioli: I want it to embody the flavor of a classic ricotta-stuffed ravioli smothered in pesto. I'm not sure what the ingredients would consist of, but it would need to taste like ricotta, basil, garlic, pine nuts, olive oil, and salt and pepper. I think this would make a great flavor because let's face it, raviolis are so good! And pesto has to be the best sauce ever created. So when you're craving a bowl of pasta in the middle of the day, you can reach for a convenient bag of ravioli pesto flavored potato chips!

Roasted Chicken Alfredo: Ingredients: Alfredo, grilled chicken flavoring. Description: Grilled chicken flavoring would be in the chip itself and the Alfredo would be powder or seasoning on the chip. Why: It sounds good to me. I have yet to see a chip use any kind of Alfredo flavoring.

Some of the least creative ideas (i.e., those rated low on both novelty and appropriateness)

Bacon: Bacon flavoring added to chips. Bacon makes everything better!

Jalapeno pepper flavored chips: The ingredients would be jalapeno pepper flavoring. I love this food and think it would be a great potato chip. It probably would taste best kettle-cooked but I think any way would work.

Potato onion chips: Ingredients - potato, onion. I think potato and onion makes a good flavor. 
ideas generated by participants in the high reward condition were rated as being more appropriate $(M=4.90, \mathrm{SD}=.84)$ than those generated by participants in either the low reward $\left(M=4.34, \mathrm{SD}=.98 ; \mathrm{Z}_{\mathrm{Mann}-\mathrm{Whitney}}=3.02, p=.003\right)$ or no reward condition $\left(M=4.38, \mathrm{SD}=.87 ; \mathrm{Z}_{\text {Mann-Whitney }}=2.92, p=.004\right)$. No significant difference was observed in the appropriateness scores of the ideas generated in the no reward and low reward conditions $(p>.25)$ (Fig. 3).

\section{Discussion and conclusion}

This study examines how monetary rewards influence consumers' participation and their level of creativity in firms' crowdsourcing initiatives. The results suggest that offering sufficiently high rewards (as opposed to either no reward at all or low rewards) is effective in encouraging more consumers to take part in an idea generation task and getting them to generate more appropriate ideas. This finding is in line with many studies in both economics and psychology that emphasize the importance of monetary rewards in directing people's attention and effort toward the activity for which those rewards are being given. One explanation for the nonsignificant difference between the no reward and low reward conditions in terms of both the appropriateness of the ideas submitted and consumers' willingness to participate in the first place could be that these rewards were simply not high enough to generate a significant change in behavior.

The more counterintuitive finding of this study is that introducing a monetary reward to stimulate new product ideation might in some cases backfire and be detrimental to creativity. This negative effect was, however, dependent on the level of monetary reward. With high levels of reward, the offer of money was not detrimental to the number of ideas generated by each participant and the novelty of those ideas, but neither was it beneficial. However, when the level of reward was relatively low, this led to fewer ideas and less novelty than when no reward was offered. One potential explanation for this finding is that offering a monetary reward might affect participants' motivation in at least two ways. First, it could lead to sorting (Lazear 2000; Rynes et al. 2005) - i.e., it might attract different kinds of participant in terms of motivation. Specifically, consumers who participate in a crowdsourcing task for which there are

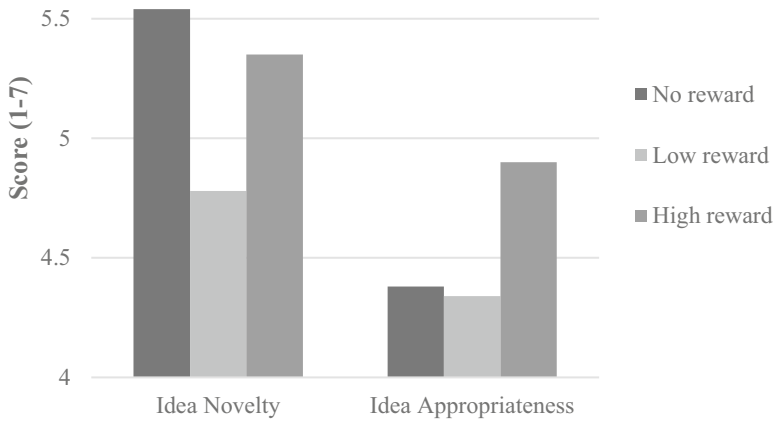

Fig. 3 Effect of monetary rewards on idea novelty and appropriateness 
no rewards are likely to be intrinsically motivated (i.e., they take part because they genuinely enjoy engaging in creative idea generation) whereas those who decide to take part in tasks for which rewards are being offered are likely to be more extrinsically motivated (i.e., their participation is driven, at least in part, by the prospect of winning a prize). Second, the provision of rewards might lead to an interpretive shift in participants' motivation - from intrinsic to extrinsic - in terms of why they are undertaking the task (Burroughs et al. 2011; Deci et al. 1999; Lepper et al. 1973). That is, when rewards are available, consumers are more likely to view their reason for engaging in an activity as being to gain a financial return, rather than to see it as an opportunity for sheer enjoyment. As intrinsic motivation is associated with sustained effort and a focus on fresh and original ideas (Amabile 1996; Grant and Berry 2011; Hennessey and Amabile 2010), consumers who engage in ideation when no rewards are offered are likely to generate both a greater number of ideas and more novel ideas. The lower level of intrinsic motivation, as a consequence of the sorting and interpretative shift effects brought about by the rewards, may render the rewards themselves ineffective, or even detrimental, in terms of stimulating a greater quantity of ideas and a greater degree of novelty. Such detrimental effects are likely to occur when the level of reward provided is not sufficient to allow extrinsic motivation to take over from intrinsic motivation in terms of motivating participants to maintain their creative effort and focus on novel ideas. When the rewards are sufficiently high, the decline in intrinsic motivation could be offset by extrinsic motivation, provided the rewards are contingent on creativity (Byron and Khazanchi 2012).

These findings have important implications for the marketing and psychology literature. First, this study helps to provide a better understanding of the dynamics of crowdsourcing and extends the limited literature on the motivational underpinnings of consumer engagement and creativity in crowdsourcing initiatives. It thereby also helps to build a greater understanding of creativity at the "front-end of innovation," which has been identified as a critical research priority (Hauser et al. 2006) and noted as an area in which the marketing literature currently provides only limited insights (Burroughs et al. 2011). Second, the study contributes to the psychology literature on the link between rewards and creativity. Specifically, to my best knowledge, it provides the first evidence to show that the effect of rewards on creativity varies depending on the size of the rewards and that rewards can impact the components of creativity (i.e., novelty and appropriateness) in different ways.

From a practical standpoint, the insights provided here can help firms to reap the benefits of their crowdsourcing initiatives more effectively. The results suggest that when the main purpose of a crowdsourcing initiative is to get novel ideas, firms may not need to offer any rewards at all. The drawback, however, is that those ideas may not be very appropriate and not as many people may be attracted to take part. When these two factors are important, firms should offer sufficiently high rewards to motivate people to take part. Whatever the objective of the crowdsourcing initiative, firms should avoid offering a low level of reward as this would be at best a waste of resources. For firms that wish to use monetary rewards to incentivize people to participate in their crowdsourcing initiatives, a natural next question to ask is what constitutes a really low reward and what level of reward will be adequate. It is impossible to suggest a specific amount that will be applicable for each and every crowdsourced task, as this would clearly depend on various contextual factors such as exactly what the task requires (e.g., simple ideas, 
detailed designs, and advertising videos), how intense the competition is (e.g., whether participants are competing with hundreds or thousands of others), whether specific expertise is required (e.g., knowledge of a specific video editing software), and various other factors. Firms should seek to find out what customers perceive to be an adequate reward, as I have done in the pretest reported in this study.

I conclude by highlighting some avenues for future research. First, in this study, a multiple-prize award structure was used, and the rewards were contingent upon being creative. I encourage future research to explore whether the findings of this study could be generalized for different reward structures and contingencies. Scholars could, for example, investigate how the relationship between reward and creativity unfolds when the rewards are provided on a winner-takes-all basis, when they are distributed differently (e.g., shared equally between multiple winners rather than awarded in order of rank), or when they are completion-contingent (e.g., offered for everyone who submits an idea). Second, increasing the level of reward beyond a certain point might lead to lower creativity due to "overmotivation" or a "choking under pressure" effect-i.e., excessive motivation for an activity can lead to a deterioration in performance (Mobbs et al. 2009). Although I found no evidence of this phenomenon in my data, future research could examine potential curvilinear (inverted U-shaped) effects of reward size on creativity by, for example, including experimental conditions where substantially higher levels of reward are used than was the case here. Third, several factors, such as who is giving the money, why it is being given, and how it is given, can also influence the symbolic meanings associated with it (Mickel and Barron 2008). Exploring the role that such meanings may play in the link between reward size and creativity is a promising avenue for future research. Fourth, it is important to know whether the type of task that is being crowdsourced has a role in the reward-creativity relationship. In particular, researchers could investigate the effects of rewards in crowdsourcing contests that focus on innovative activities that differ from new product ideation in terms of their complexity (e.g., R\&D problems) or the level of engagement and expertise required (e.g., creating copy for an ad or developing a product prototype) (Acar and Puntoni 2016; Acar and van den Ende 2015; Terwiesch and Xu 2008). Finally, the explanations I provide for why reward size may affect creativity in different ways are conjectural. Future research is needed to establish whether changes in the level of intrinsic or extrinsic motivation do indeed account for these findings. In addition, researchers could also explore other potential mediators, which may include cognitive processes such as search variation and effort (Acar and van den Ende 2016), and affective factors such as positive and negative mood (Baas et al. 2008).

I hope that the insights provided in this study will take us one step closer to understanding what part motivation plays in new product ideation and will help managers to make more informed decisions on how to reward consumers for their creativity.

Open Access This article is distributed under the terms of the Creative Commons Attribution 4.0 International License (http://creativecommons.org/licenses/by/4.0/), which permits unrestricted use, distribution, and reproduction in any medium, provided you give appropriate credit to the original author(s) and the source, provide a link to the Creative Commons license, and indicate if changes were made. 


\section{References}

Acar, O. A., \& Puntoni, S. (2016). Customer empowerment in the digital age. Journal of Advertising Research, 56(1), 4-8.

Acar, O. A., \& van den Ende, J. (2015). Understanding fear of opportunism in global prize-based science contests: evidence for gender and age differences. PLoS One, 10(7), e0134898.

Acar, O. A., \& van den Ende, J. (2016). Knowledge distance, cognitive-search processes and creativity: the making of winning solutions in science contests. Psychological Science, 27(5), 692-699.

Ales, L., Cho, S., \& Korpeoglu, E. (2017). Optimal award scheme in innovation tournaments. Operations Research, 65(3), 693-702.

Amabile, T. (1996). Creativity in context. Boulder: Westview Press.

Baas, M., De Dreu, C. K. W., \& Nijstad, B. A. (2008). A meta-analysis of 25 years of mood-creativity research: hedonic tone, activation, or regulatory focus? Psychological Bulletin, 134(6), 779-806.

Bayus, B. L. (2013). Crowdsourcing new product ideas over time: an analysis of the Dell ideastorm community. Management Science, 59(1), 226-244.

Burroughs, J. E., Dahl, D. W., Moreau, C. P., Chattopadhyay, A., \& Gorn, G. J. (2011). Facilitating and rewarding creativity during new product development. Journal of Marketing, 75(4), 53-67.

Byron, K., \& Khazanchi, S. (2012). Rewards and creative performance: a meta-analytic test of theoretically derived hypotheses. Psychological Bulletin, 138(4), 809-830.

Deci, E. L., Koestner, R., \& Ryan, R. M. (1999). A meta-analytic review of experiments examining the effects of extrinsic rewards on intrinsic motivation. Psychological Bulletin, 125(6), 627-668.

Eisenberger, R., \& Armeli, S. (1997). Can salient reward increase creative performance without reducing intrinsic creative interest? Journal of Personality and Social Psychology, 72(3), 652-663.

Eisenberger, R., \& Aselage, J. (2009). Incremental effects of reward on experienced performance pressure: positive outcomes for intrinsic interest and creativity. Journal of Organizational Behavior, 30(1), 95-117.

Eisenberger, R., \& Selbst, M. (1994). Does reward increase or decrease creativity? Journal of Personality and Social Psychology, 66(6), 1116-1127.

Fuchs, C., Prandelli, E., \& Schreier, M. (2010). The psychological effects of empowerment strategies on consumers' product demand. Journal of Marketing, 74(1), 65-79.

Gneezy, U., \& Rustichini, A. (2000). Pay enough or don't pay at all. Quarterly Journal of Economics, 115(3), 791-810.

Grant, A. M., \& Berry, J. W. (2011). The necessity of others is the mother of invention: intrinsic and prosocial motivations, perspective taking, and creativity. Academy of Management Journal, 54(1), 73-96.

Guilford, J. P. (1967). The nature of human intelligence. New York: McGraw-Hill.

Hauser, J., Tellis, G. J., \& Griffin, A. (2006). Research on innovation: a review and agenda for marketing science. Marketing Science, 25(6), 687-717.

Hennessey, B. A., \& Amabile, T. (2010). Creativity. Annual Review of Psychology, 61(1), 569-598.

Heyman, J., \& Ariely, D. (2004). Effort for payment a tale of two markets. Psychological Science, 15(11), 787-793.

Huang, Y., Singh, P., \& Srinivasan, K. (2014). Crowdsourcing new product ideas under consumer learning. Management Science, 60(9), 2138-2159.

Lazear, E. (2000). The power of incentives. The American Economic Review, 90(2), 410-414.

Lepper, M. R., Greene, D., \& Nisbett, R. E. (1973). Undermining children's intrinsic interest with extrinsic reward: a test of the "overjustification" hypothesis. Journal of Personality and Social Psychology, 28(1), $129-137$.

Mehta, R., \& Zhu, R. J. (2009). Blue or red? Exploring the effect of color on cognitive task performances. Science, 323(5918), 1226-1229.

Mehta, R., \& Zhu, M. (2016). Creating when you have less: the impact of resource scarcity on product use creativity. Journal of Consumer Research, 42(5), 767-782.

Mehta, R., Zhu, R. J., \& Cheema, A. (2012). Is noise always bad? Exploring the effects of ambient noise on creative cognition. Journal of Consumer Research, 39(4), 784-799.

Mickel, A. E., \& Barron, L. A. (2008). Getting "more bang for the buck": symbolic value of monetary rewards in organizations. Journal of Management Inquiry, 17(4), 329-338.

Mobbs, D., Hassabis, D., Seymour, B., Marchant, J. L., Weiskopf, N., Dolan, R. J., \& Frith, C. D. (2009). Choking on the money. Reward-based performance decrements are associated with midbrain activity. Psychological Science, 20(8), 955-963.

Moreau, C. P., \& Dahl, D. W. (2005). Designing the solution: the impact of constraints on consumers' creativity. Journal of Consumer Research, 32(1), 13-22. 
Poetz, M. K., \& Schreier, M. (2012). The value of crowdsourcing: can users really compete with professionals in generating new product ideas? Journal of Product Innovation Management, 29(2), 245-256.

Prendergast, C. (1999). The provision of incentives in firms. Journal of Economic Literature, 37(1), 7-63.

Rynes, S. L., Gerhart, B., \& Parks, L. (2005). Personnel psychology: performance evaluation and pay for performance. Annual Review of Psychology, 56, 571-600.

Stephen, A. T., Zubcsek, P. P., \& Goldenberg, J. (2016). Lower connectivity is better: the effects of network structure on redundancy of ideas and customer innovativeness in interdependent ideation tasks. Journal of Marketing Research, 53(2), 263-279.

Terwiesch, C., \& Xu, Y. (2008). Innovation contests, open innovation, and multiagent problem solving. Management Science, 54(9), 1529-1543.

Toubia, O. (2006). Idea generation, creativity, and incentives. Marketing Science, 25(5), 411-425. 